\title{
From the Desk of Editor-in-Chief
}

This is a great pleasure that Journal of Enam Medical College has been being published regularly since January 2011. By this time, the journal has been appreciated by the scientific community of the country and it is running in parallel with other established journals of the country. We are highly thankful to the Almighty for the success we have achieved so far. We promise to improve it further with active cooperation of the academic faculty of the college. Measures are in progress for recognition of the journal by Bangladesh Medical and Dental Council (BMDC) and to index the journal in internationally reputed databases.

Our sincere appreciation always goes to all the contributors and reviewers who have devoted their talents to make the journal glamorous one. We also convey our gratitude to Principal and Chairman of Enam Medical College for their whole-hearted continuous support and guidance in publishing the journal regularly.

In the previous issue of the journal we committed that the journal will be available online from July 2012. Now it is available online in BanglaJOL, AsiaJOL, in the website of Enam Medical College (http://emcbd.com/) and newly opened separate website exclusively for the journal (http://journalemc.com/). We hope that online publication of the journal will disseminate the research activities of our scientists to the world scientific community. In this issue we have published two research papers from abroad. We hope it will enrich the journal and give our readers a different flavour of taste.

The editors of the journal have invested their utmost efforts to make the journal as smart and scientific as possible. No stone remains unturned for the perfection of the every issue of the journal. In spite of the sincerest efforts, some errors or mistakes may be noticed. Any constructive suggestion regarding the development of the journal in future is always welcomed.

Hope to give new and latest development in the next issue.

With best wishes.

\section{Prof. A. K. M. Rafique Uddin}

Editor-in-Chief 